\title{
Experimental Study of the Drying of Hot Red Pepper in the Open Air, under Greenhouse and in a Solar Drier
}

\author{
Abdelhamid Fadhel ${ }^{1}$, Sami Kooli ${ }^{1}$, Abdelhamid Farhat $^{1}$ and Ali Belghith ${ }^{2}$ \\ ${ }^{1}$ The Thermal Process Laboratory, The Research and Technology Center of Energy, Hammam-lif BP, \\ Tunisia \\ ${ }^{2}$ Department of Physics, Faculty of Sciences Mathematics, Physics and Natural of Tunis, Belvèdère, \\ Tunisia
}

Correspondence should be addressed to: Abdelhamid Fadhel; fad_ham@yahoo.fr

Received 13 May 2013; Accepted 5 November 2013; Published 31 December 2013

Academic Editor: Mohammad Ali Basunia

Copyright (C) 2014 Abdelhamid Fadhel, Sami Kooli, Abdelhamid Farhat and Ali Belghith. Distributed under Creative Commons CC-BY 3.0

\begin{abstract}
This work attempts to assess the efficiency and profitability of the greenhouse (used in agriculture) to dry agricultural products. It aims at studying and analyzing the drying of red pepper known as "Baklouti" by three different solar processes. These three drying processes enable us to profit from a free energy coming from the sun. Two experimental devices were used. Three drying kinetics were set up in a natural convection solar drier, under greenhouse and in open sun, respectively. Drying times (including nights) are about 73 hours in the dryer, 79 hours in the greenhouse and 118 hours in open sun. Six thin-layer drying models (Newton, Henderson and Pabis, Modified Henderson and Pabis, Wang and Singh, Logarithmic and Twoterm) were fitted to the experimental data to select a suitable drying equation. The Logarithmic was found to best describe the drying behavior of pepper for open sun, greenhouse and solar drier drying. The experimental results show that the solar tunnel greenhouse dryer must be improved to become competitive to the solar air dryer.
\end{abstract}

Keywords: Open sun drying; greenhouse drying; drying kinetics; solar drier; red Pepper.

\section{Introduction}

Pepper is one the most widely used ingredients in the world and is highly demanded in the international business of food industry [1, 2]. Pepper is highly produced in the summer season in Tunisia (production reaches about $250 \quad 10^{3}$ tones/year) [3]. It is a source of vitamins, minerals and energy in the human diet [4]. However, they are perishable crops, which deteriorate within a few days after harvest (which occurs mainly in the hot and wet season). Preserving their alimentary characteristics can be done by drying. In general, red pepper may undergo some specific treatments in order to slow down some of the chemical reactions that are non-enzymatic. Bleaching pepper with hot water for a period of $5 \mathrm{~min}$ causes an increase in initial moisture content and an increase in drying time [5]. Nevertheless, 
other different methods of pre-treatment which can improve the color of dried, then ground, pepper, and accelerate the drying process conspicuously $[6,7,8,9]$.

Drying, using solar energy can be done by traditional sun drying or through the use of solar dryer. In Tunisia, the traditional method of drying pepper consists in attaching the stems of pepper pods with a rope to form a garland or in cutting longitudinally these pods in two slices, and then they are dried in the open sun. Open air natural sun drying presents some problems making this operation not always suited to large scale production. Among them, the most important one are: lack of ability to control the drying operation properly, the length of the drying time, whether uncertainties, high labor costs, large area requirement and insect infestation, mixing with dust and other foreign materials and so on.

Natural convection solar driers are supposed to provide a considerable financial profitability in order to be introduced and proliferated in tropical and subtropical zones. However, in Tunisia, solar drying has been restricted to family use in order to dry few quantities of agricultural products, because of their relatively high costs and limited capacities. These inconveniences have always prevented the use of the natural convection solar driers on a large scale [10].

Plastic tunnel greenhouses have a great potential in Tunisia. These can be exploited in summer, when inside temperature is very high, for drying agricultural products and may become a more convenient alternative.

Farhat et al. [11] validated the Passamia and Saravia model $[12,13]$ on the red pepper under greenhouse tunnel and in open-air. Sacilik et al. [14] studied the characteristics of drying a thin layer of tomatoes in a greenhouse tunnel under the climatic conditions of Ankara. Rathore and Panwar [15] evaluated the performance of drying the seedless grapes in hemi cylindrical walk-in type tunnel dryer. They noticed that the latter needed seven days to dry the grapes chemically untreated at a (wb) moisture content of $16 \%$.

Kooli et al. [16] achieved experiments of drying of red pepper in open sun and under greenhouse to validate a model based on experiments conducted in the laboratory, where solar radiation was simulated by a 1000W lamp. Akpinar and Bicer [4] carried out an experimental study to determine the drying characteristics of a thin layer of pepper in open air and in a forced convection solar dryer. Kaewkiewet al. [17] presented an experimental study of the performance of a large-scale greenhouse type solar dryer for drying chilli in Thailand. This experimental investigation led them to conclude that solar greenhouse dryer is less time consuming as compared with the natural sun drying, and the colour of products dried in the solar greenhouse dryer is better than natural sun dried samples.

The main objective of this experimental study is to study and compare the thin layer drying characteristics of red pepper in the open-sun, under greenhouse and in a solar drier. The profitability of each dryer and the identification of the most convenient one will be given.

\section{Materials and methods}

\section{Experimental Devices}

The experimental study consists in implementing of the following two experimental devices:

- The first device enables us to study solar drying under greenhouse and in the open air. It consists, essentially, of a data acquisition and processing system, and a precision balance, inserted in a wooden cage (Figs.1a and 1c). For the open air tests, the perforated metal grid containing the product was surrounded from its four sides by a bell formed of four pieces of ordinary thin glass, supported by a wooden base to prevent deterioration caused by excessive air currents (Figs. $1 \mathrm{a}$ and 2a). The agricultural greenhouse used for drying which was installed in our laboratory, with an area of $100 \mathrm{~m}^{2}$ (12.5 m long and $8 \mathrm{~m}$ 
wide), and its axis is parallel to the eastwest direction. To protect it from the prevailing wind (north-western), we surrounded it by a $3 \mathrm{~m}$ height windshield. The greenhouse was covered with a plastic cover (polyethylene with low density thickness $180 \mu \mathrm{m})$.

- The second device consists of an indirect natural convection solar drier type, and a device of weighing adapted to measure uninterruptedly the weight of the product, without getting it out of the desiccation case. A longitudinal section of the drier and the weighing device are shown in Fig. 2 b.

In this study, no pre-treatment was made. The pods of the pepper ("Baklouti" variety) were cut longitudinally in two slices. After the removal of stems and seeds, fruits were spread on a perforated metal grid, the skin against the grid.

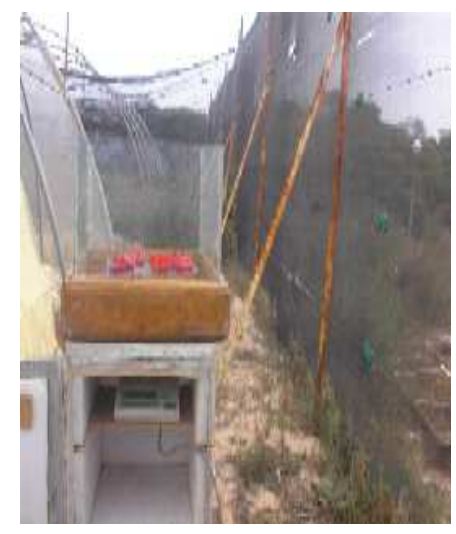

Fig. 1a. Drying Peppers in the Open Air

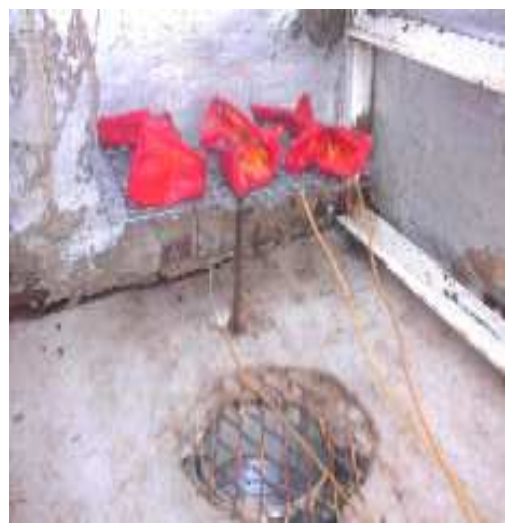

Fig. 1b. Drying Peppers in a Solar Dryer

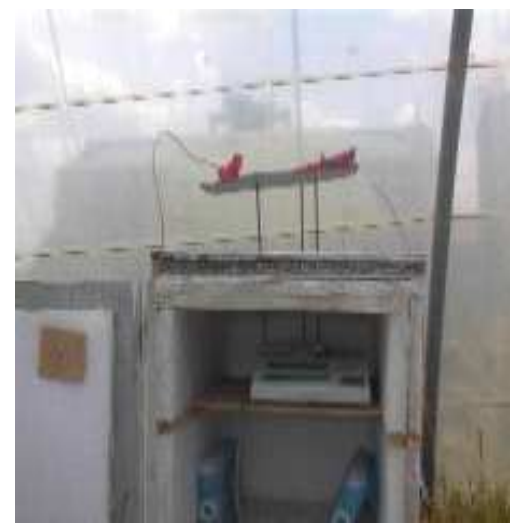

Fig. 1c. Drying Peppers under Greenhouse

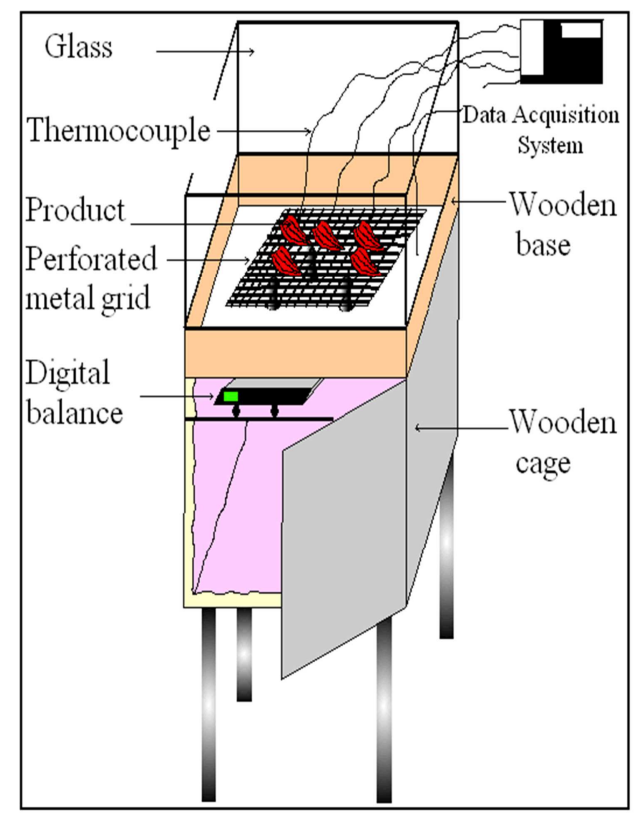

Fig. 2a. Schematic of the First Device: Under Greenhouse and Open Sun

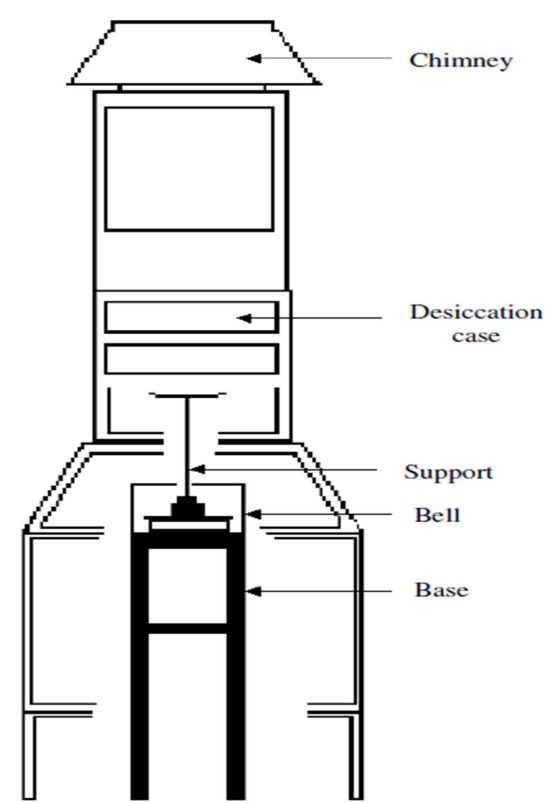

Fig. 2b. Schematic of the Second Device: Indirect Type Natural Convection Solar Drier 


\section{Drying Procedure and Data Acquisition}

In the drying tests under greenhouse, in the open air and in the drier, the drying parameters are continuously variable through time (variable conditions). To measure the product temperature, three thermocouples type $\mathrm{K}$ were used. The product temperature is obtained by averaging the temperatures of these three thermocouples that are placed in different locations in the product (Figs. 1a, 1b and 1c). The air speed passing through the three systems was measured by a $0-15 \mathrm{~m} / \mathrm{s}$ range anemometer (TESTO 440). The relative humidity and air temperature were measured by a sensor HMP35C (Vaisala model HMP35C). Solar radiation is measured with a pyranometer LI-5 200SZ LiCor (model LI-200) in a range of 0 $1000 \mathrm{~W} / \mathrm{m}^{2}$.The recordings were made by connecting thermocouples and HMP35C probe to a 21X CAMPBELL Scientific Data Acquisition System enabling us to record the experimental data for the temperatures, and for the relative humidity. The mass of the sample through time was measured by a $600 \mathrm{~g}$ weighing capacity balance (METTLER-TOLEDO). The product temperature on the perforated metal grid, the air temperature, the relative humidity of the air around the product surface and the mass of the sample were measured at intervals of 20 min during the experiments. The data acquisition and the data processing are done through a personal computer and through an IEEE connection. Once the operation of drying is finished, the sample is placed in an oven drying at $120^{\circ} \mathrm{C}$ for 12 hours and then weighed to determine its dry matter.

\section{Mathematical Modelling of Drying Curves}

Pepper slices water content was estimated on dry basis. Dry matter value of the samples was calculated. The product water content at different drying stages was then expressed according to the following relation:

$X=\frac{m_{e}}{m_{s}}=\frac{m-m_{s}}{m_{s}}$

Where $m_{e}$ is the mass of the product water, $\mathrm{X}$ the water content in dry basis, $\mathrm{m}$ the mass of the product and $m_{s}$ the corresponding dry matter.

\begin{tabular}{|c|c|c|c|}
\hline \multicolumn{4}{|l|}{ Nomenclature } \\
\hline$a, b, c, g, h$ & empirical constants in the drying models & $\mathrm{X}$ & moisture content, (dry basis) \\
\hline DR & dying rate, (\% dry basis/h) & $\mathrm{X}_{0}$ & initial moisture content, (dry basis) \\
\hline Ge & solar radiation outside greenhouse, $\left(\mathrm{W} / \mathrm{m}^{2}\right)$ & $\mathrm{X}_{\mathrm{eq}}$ & $\begin{array}{l}\text { equilibrium moisture content, ( dry } \\
\text { basis) }\end{array}$ \\
\hline Gi & solar radiation inside greenhouse, $\left(\mathrm{W} / \mathrm{m}^{2}\right)$ & $\mathrm{X}_{\mathrm{t}}$ & moisture content at t (dry basis) \\
\hline $\mathrm{k}, \mathrm{k}_{0}, \mathrm{k}_{1}$ & empirical constants in the drying models & $\mathrm{X}_{\mathrm{t}+\mathrm{dt}}$ & moisture content at $\mathrm{t}+\mathrm{dt}$ (dry basis) \\
\hline $\mathrm{m}$ & mass of the product, $(\mathrm{kg})$ & $\mathrm{XR}$ & moisture ratio \\
\hline$m_{e}$ & mass of the product water, $(\mathrm{kg})$ & $\mathrm{XR}_{\mathrm{exp}}$ & experimental moisture ratio \\
\hline $\mathrm{m}_{\mathrm{s}}$ & dry matter of the product, $(\mathrm{kg})$ & $\mathrm{XR}_{\mathrm{pr}}$ & predicted moisture ratio \\
\hline $\mathrm{n}$ & number constants & $\mathrm{t}$ & time, (h) \\
\hline $\mathrm{N}$ & number of observations & Та & air temperature, $\left({ }^{\circ} \mathrm{C}\right)$ \\
\hline $\mathrm{R}^{2}$ & correlation coefficient & $\mathrm{Tp}$ & product temperature, $\left({ }^{\circ} \mathrm{C}\right)$ \\
\hline RH & relative humidity of the air, (\%) & & \\
\hline RMSE & root mean square error & \multicolumn{2}{|c|}{ Subscripts } \\
\hline$w_{R}$ & total uncertainty in measurement of result & Av & the average value \\
\hline$w_{1}, W_{2}, . ., w_{n}$ & the uncertainties in independent variables & $\operatorname{Max}$ & the maximum value \\
\hline$w_{m l}$ & $\begin{array}{l}\text { total uncertainty in the measurement of mass } \\
\text { loss values }\end{array}$ & Min & the minimum value \\
\hline$w_{m q}$ & $\begin{array}{l}\text { total uncertainty in the measurement of the } \\
\text { moisture quantity }\end{array}$ & & \\
\hline$w_{t m}$ & $\begin{array}{l}\text { total uncertainty in the measurement of time of } \\
\text { mass loss values }\end{array}$ & \multicolumn{2}{|c|}{ Greek symbol } \\
\hline$W_{D R}$ & total uncertainty in the calculated of drying rate & $\chi^{2}$ & chi-square \\
\hline$w_{X R}$ & $\begin{array}{l}\text { total uncertainty in the calculated of moisture } \\
\text { rate }\end{array}$ & & \\
\hline
\end{tabular}


To compare the experimental results, we propose to transform the moisture content $(\mathrm{X})$ in the moisture ratio (XR).The moisture ratio (XR) of pepper slices during drying were calculated using the following equation:

$X R=\frac{X-X_{e q}}{X_{0}-X_{e q}}$

Where $\mathrm{X}, \mathrm{X}_{0}$ and $\mathrm{X}_{\mathrm{eq}}$ (kg water/kg dry matter) are, respectively, the moisture content at a specific time, the initial moisture content, the equilibrium moisture content.

Drying rates (DR) were then estimated by differentiation of water content with respect to time as:

$D R=\frac{d X}{d t}=\frac{X_{t+d t}-X_{t}}{d t}$

WhereX $\mathrm{X}_{\mathrm{t}}$ and $\mathrm{X}_{\mathrm{t}+\mathrm{dt}}$ (kg water/kg dry matter) are the moisture content at the moment $t$ and the moisture content at the moment $\mathrm{t}+\mathrm{dt}$, respectively.

For mathematical modelling, the thin layer drying equations in Table 1 were tested to select the best model for describing the drying curve equation of red pepper during drying by the solar dryer, under greenhouse and in open sun. Regression analysis was performed using the Statistica computer program. The correlation coefficient $\left(\mathrm{R}^{2}\right)$ was the primary criterion for selecting the best equation to describe the drying curve equation. In addition to $\mathrm{R}^{2}$, the reduced $\chi^{2}$ as the mean square of the deviations between the experimental and calculated values for the models and the root mean square error analysis (RMSE) were used to determine the goodness of the fit. Higher values of $\mathrm{R}^{2}$ and lower values of $\chi^{2}$ and RMSE indicate better goodness of fit $[4,18,19,20,21,22]$. These can be calculated as:

$$
\begin{aligned}
& R^{2}=1-\frac{\sum_{i=1}^{N}\left(X R_{\text {exp }, i}-X R_{\text {pre }, i}\right)^{2}}{\sum_{i=1}^{N}\left(\overline{X R}_{\text {exp }, i}-X_{\text {exp }, i}\right)^{2}} \\
& \chi^{2}=\frac{\sum_{i=1}^{N}\left(X R_{\text {exp }, i}-X R_{\text {pre }, i}\right)^{2}}{N-n} \\
& R M S E=\left[\frac{1}{N} \sum_{i=1}^{N}\left(X R_{\text {pre }, i}-X R_{\text {exp }, i}\right)^{2}\right]^{\frac{1}{2}}
\end{aligned}
$$

Where $\mathrm{XR}_{\text {exp, } \mathrm{i}}$ is the $i$ th experimental moisture ratio, $\mathrm{XR}_{\mathrm{pre}, \mathrm{i}}$ is the $i$ th predicted moisture ratio, $\overline{X R}_{\text {exp }, i}$ the mean experimental moisture ratio, $N$ the number of observations, and $n$ the number of constants in each regression model.

Table 1. Mathematical Models Widely Used to Describe Drying Kinetics

\begin{tabular}{|l|l|l|l|}
\hline Model no. & Model name & Model & Reference \\
\hline 1 & Newton & XR $=\exp (-\mathrm{kt})$ & {$[23]$} \\
\hline 2 & Henderson and Pabis & $\mathrm{XR}=\operatorname{aexp}(-\mathrm{kt})$ & {$[24]$} \\
\hline 3 & Logarithmic & $\mathrm{XR}=\operatorname{aexp}(-\mathrm{kt})+\mathrm{c}$ & {$[25]$} \\
\hline 4 & Two-term & $\mathrm{XR}=\mathrm{aexp}\left(-\mathrm{k}_{0} \mathrm{t}\right)+\mathrm{bexp}\left(-\mathrm{k}_{1} \mathrm{t}\right)$ & {$[26]$} \\
\hline 5 & Wang and Singh & $\mathrm{XR}=1+\mathrm{at}+\mathrm{bt}^{2}$ & {$[27]$} \\
\hline 6 & $\begin{array}{l}\text { Modified Henderson and } \\
\text { Pabis }\end{array}$ & $\begin{array}{l}\mathrm{XR}=\mathrm{aexp}(-\mathrm{kt})+\mathrm{bexp}(-\mathrm{gt})+\operatorname{cexp}(- \\
\mathrm{ht})\end{array}$ & {$[28]$} \\
\hline
\end{tabular}

\section{Uncertainty Analysis}

The calculated uncertainties of the dependent parameters were estimated by Eq. (7). The result $R$ is a given function in terms of the independent variables. Let $w_{R}$ be the uncertainty in the result and $w_{1}, w_{2}$. . . , $w_{n}$ be the uncertainties in the independent variables. The result $R$ is a given function of the independent variables $x_{1}, x_{2}, \ldots, x_{n}$. If the uncertainties in the independent variables are all given with the same odds, then the uncertainty in the result having these odds is calculated by:

$$
\begin{aligned}
& w_{R}= \\
& \left.\left(\frac{\partial R}{\partial x_{n}} w_{n}\right)^{2}\right]^{\frac{1}{2}}
\end{aligned}
$$


Uncertainty analysis is needed to prove the accuracy of the experiments. The independent parameters measured in the experiments reported here are air temperature, product temperature, relative humidity of the air, air velocity, solar radiations, and mass of the sample. To carry out these experiments, the sensitiveness of data acquisition system is about $\pm 0.01{ }^{\circ} \mathrm{C}$, the measurement error is $\pm 0.02{ }^{\circ} \mathrm{C}$, and the sensitiveness of the thermocouple is $\pm 0.01^{\circ} \mathrm{C}$. The HMP35C errors are $\pm 0.1^{\circ} \mathrm{C}$ of temperature and $\pm 3 \%$ of humidity. An anemometer with $\pm 0.1 \mathrm{~ms}^{-}$ 1accuracy, pyranometer with $\pm 5 \%$ accuracy, and balance with $\pm 0.1 \mathrm{~g}$ measurements uncertainties are used. The sensitiveness was obtained from catalogs of the instruments.

From these measured data, total uncertainties of the moisture ratio (XR) and drying rate (DR) of pepper may be calculated:

$$
\begin{aligned}
w_{X R} & =w_{D R}=\left[\left(w_{t m}\right)^{2}+\left(w_{m l}\right)^{2}+\left(w_{m q}\right)^{2}\right]^{\frac{1}{2}} \\
& = \pm 0.18
\end{aligned}
$$

Where $w_{t m}, w_{m l}$ and $w_{m q}$ are, respectively, the total uncertainty in the measurement of time of mass loss values, the total uncertainty in the measurement of mass loss values, the total uncertainty in the measurement of the moisture quantity.

\section{Results and Discussion}

Drying tests conducted on red pepper in solar drier, in greenhouse, and open sun, were performed on different time intervals: in the greenhouse during the month of August, in the open air during the month of September and into the drier during the period of the late August and early September of the following year. The drying parameters (air temperature, relative humidity of air, solar radiation and air speed) were in continuous variation during the time. During the drying experiments (Table 2), the temperature of ambient air ranged from 18.21 to $33.57^{\circ} \mathrm{C}$. The maximum instantaneous solar radiation ranged from 812 to $902 \mathrm{~W} / \mathrm{m}^{2}$. The relative humidity of ambient air ranged from 53.5 to $91.9 \%$. It decreases during the day and increases during the night. Moreover, the average ambient air temperature, the average solar radiation and the average relative humidity of the air during the drying tests in solar drier, in greenhouse, and open sun are similar (Table 2). The climatic conditions during these three periods are quite similar. Therefore the experimental results can be compared on the same scale of time.

\begin{tabular}{|c|c|c|c|}
\hline Drying process & Open sun & Greenhouse & Drier \\
\hline $\mathrm{Ta}_{\operatorname{Min}}\left({ }^{\circ} \mathrm{C}\right)$ & 18.21 & 23.26 & 25.14 \\
\hline $\mathrm{Ta}_{\operatorname{Max}}\left({ }^{\circ} \mathrm{C}\right)$ & 32.12 & 30.98 & 33.57 \\
\hline $\mathrm{Ta}_{\mathrm{Av}}\left({ }^{\circ} \mathrm{C}\right)$ & 26.02 & 26.64 & 28.17 \\
\hline $\mathrm{Ge}_{\operatorname{Max}}\left(\mathrm{W} / \mathrm{m}^{2}\right)$ & 812 & 902 & 880 \\
\hline $\mathrm{Ge}_{\mathrm{Av}}\left(\mathrm{W} / \mathrm{m}^{2} \mathrm{~h}^{1}\right)$ & 380 & 382 & 393 \\
\hline $\mathrm{RH}_{\operatorname{Min}}(\%)$ & 53.5 & 65.8 & 58.7 \\
\hline $\mathrm{RH}_{\operatorname{Max}}(\%)$ & 83.5 & 82.8 & 91.9 \\
\hline $\mathrm{RH}_{\mathrm{Av}}(\%)$ & 69.5 & 77.1 & 77.5 \\
\hline
\end{tabular}

\section{Table 2. Drying Periods Climatic Conditions}

During the drying experiments (Fig. 3) the temperature around the product in the drier desiccation case ranged from 24.65 to $48.52^{\circ} \mathrm{C}$, the temperature of the drying air in the greenhouse ranged from 23.05 to $46.6^{\circ} \mathrm{C}$ and the temperature of the ambient air in open sun ranged from 18.21 to $32.12^{\circ} \mathrm{C}$. During night, the air temperature curves around the product touch that of the ambient air temperature. During the day, the air temperature around the product in the drier and in the greenhouse is higher than the ambient air temperature. We recorded a maximum temperature difference in the drier of about $22.9{ }^{\circ} \mathrm{C}$ and in the greenhouse of about $16.6^{\circ} \mathrm{C}$. 


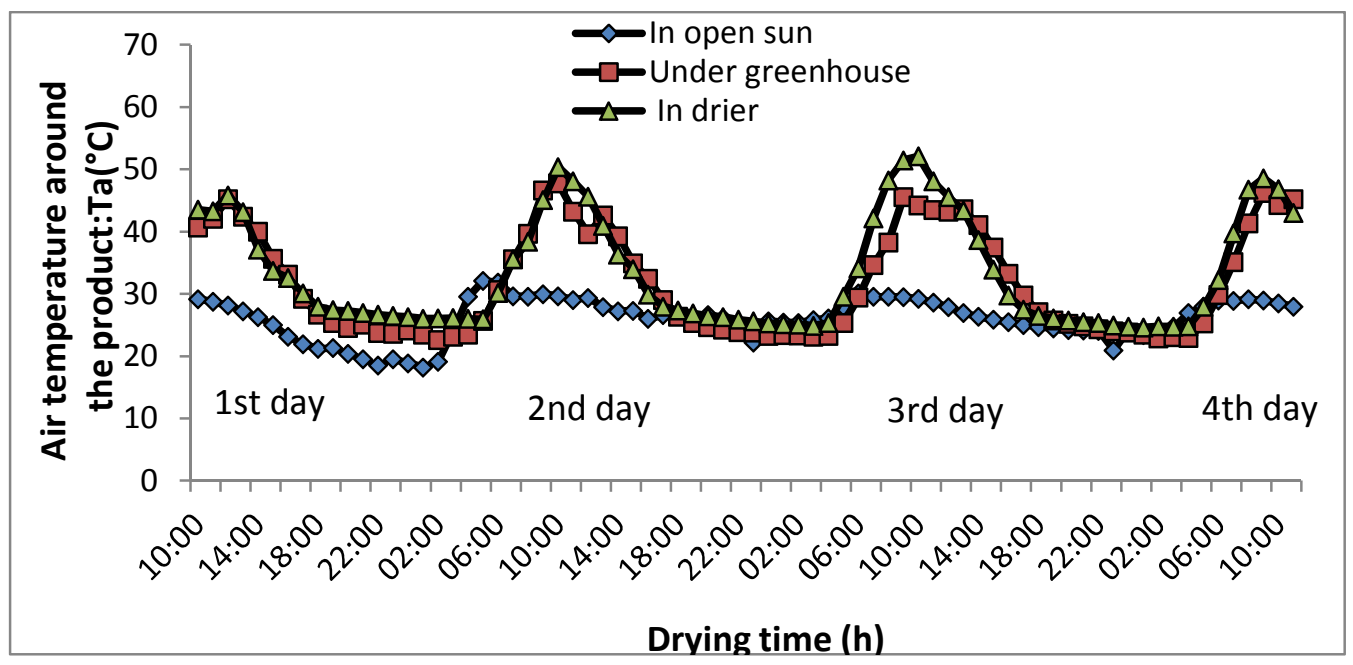

Fig. 3. Variation of the Air Temperature around the Product with Drying Time

The temperature of the product (Fig. 4) in the drier desiccation case ranged from 24.47 to $48.17{ }^{\circ} \mathrm{C}$, in the greenhouse ranged from 21.68 to $55.44{ }^{\circ} \mathrm{C}$ and in open sun ranged from 16.43 to $51.92{ }^{\circ} \mathrm{C}$. During the night the product temperature curves touch those of drying air temperature. During the day, in open air and in the greenhouse, the product temperatures are higher than the drying air temperatures. We recorded a maximum temperature difference in open air of about $22.37^{\circ} \mathrm{C}$ and in the greenhouse of about $10.21^{\circ} \mathrm{C}$. However, in the drier, the drying air temperature is higher than the product temperature. We recorded a maximum temperature difference of about $5.08^{\circ} \mathrm{C}$.

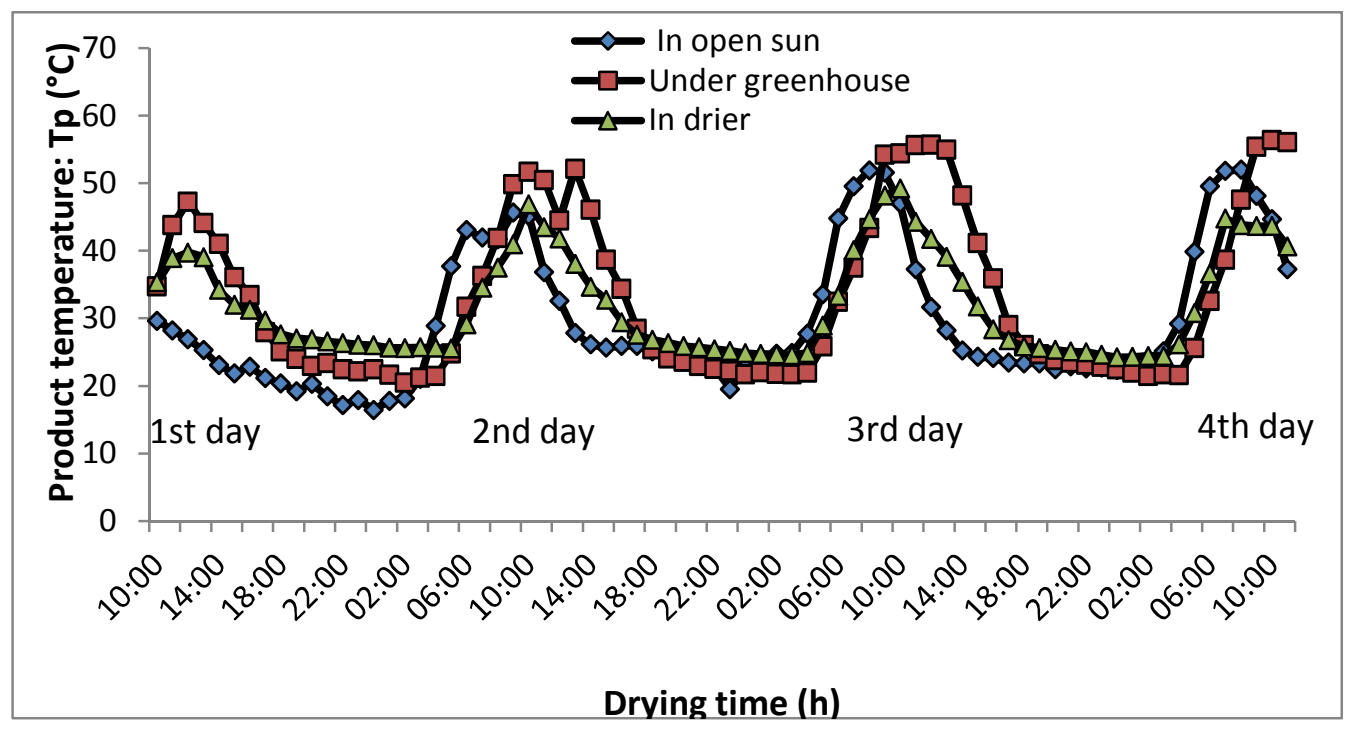

Fig. 4. Variation of the Product Temperature with Drying Time

The solar radiation energy flux incident just about the product in open sun and under greenhouse during the experimental periods was plotted against drying time in Fig. 5. The solar radiation in the greenhouse is less intense than that of outside. We recorded a reduction about $20 \%$ in the radiation penetrating the greenhouse cover. Direct instantaneous solar radiation reached $812 \mathrm{~W} / \mathrm{m}^{2}$ in open sun, and $678 \mathrm{~W} / \mathrm{m}^{2}$ in greenhouse. 


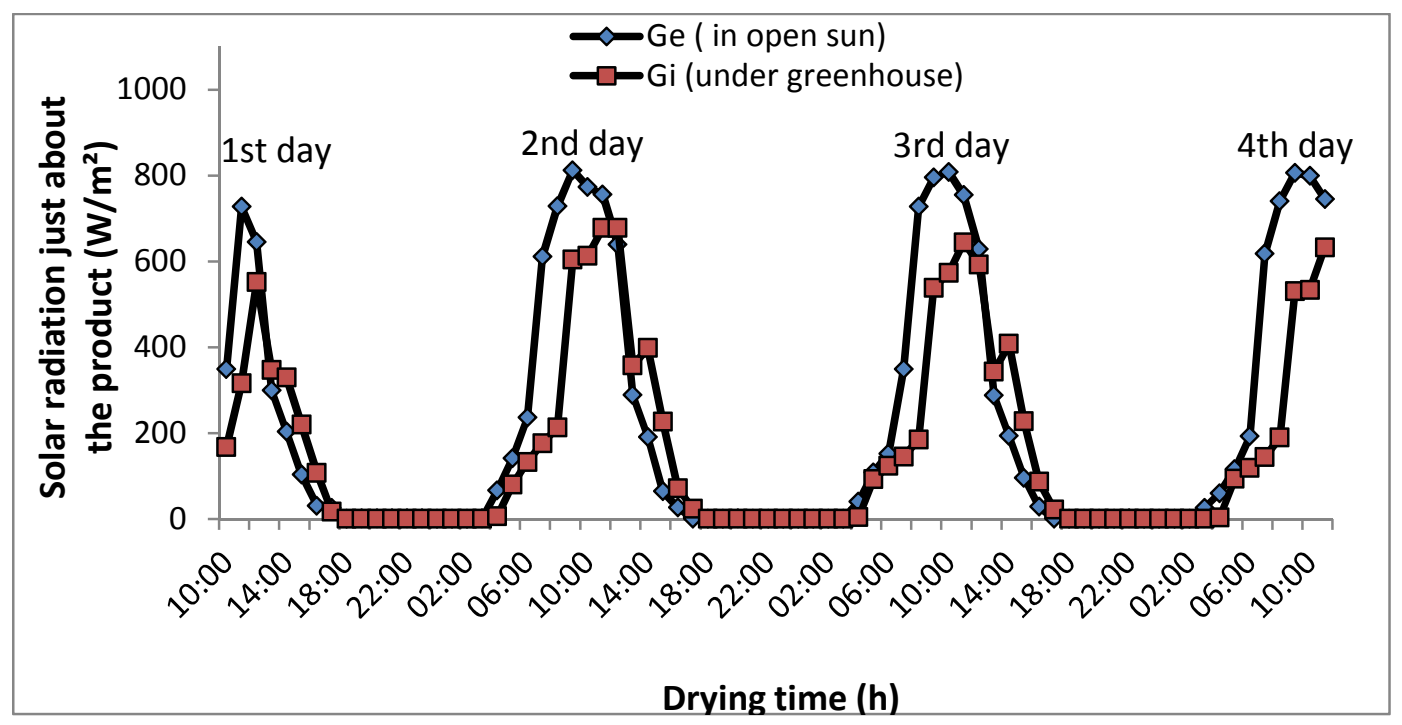

Fig. 5. Variation of Solar Radiation Just about the Product with Drying Time

Fig. 6 shows the variation curves of the air relative humidity around the product in open sun, under greenhouse and in the drier with drying time. The relative humidity decreases during the day and increases during the night. The relative humidity of air in open sun ranged from 53.5 to $83.5 \%$, in the greenhouse ranged from 17.8 to $93.4 \%$, and in the drier ranged from 12.0 to $100 \%$. During the day, the relative humidity of the air inside the drier is lower than that inside the greenhouse and in open sun. Low relative humidity is more favourable for drying due to the increase of the evaporating capacity of the air. During the night, relative humidity of the air inside the drier and relative humidity inside the greenhouse were higher than that of air in open sun. The excessive increase in the relative humidity of the air, during the night in the drier and inside the greenhouse can increase the moisture content of the product.

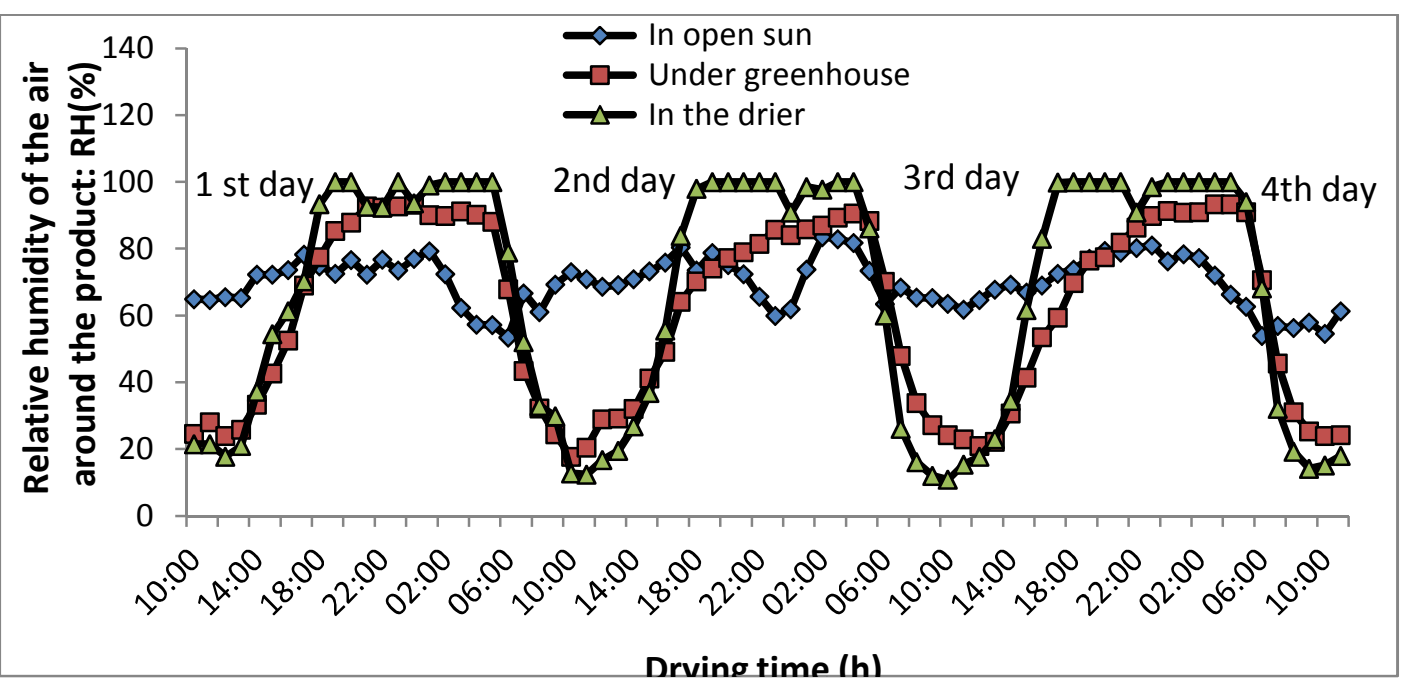

Fig. 6. Variation of Relative Humidity of the Air around the Product with Drying Time

The drying kinetics of pepper with drying time is shown in Fig. 7. Drying of red peppers was started with an initial moisture content of $10.1 \mathrm{~kg}$ water/kg dry 
matter in open sun, $12.6 \mathrm{~kg}$ water $/ \mathrm{kg}$ dry matter under greenhouse and $7.97 \mathrm{~kg}$ water $/ \mathrm{kg}$ dry matter into the drier. The final moisture contents were $0.18 \mathrm{~kg}$ water $/ \mathrm{kg}$ dry matter in the dryer, $0.72 \mathrm{~kg}$ water/kg dry matter in the greenhouse and $0.55 \mathrm{~kg}$ water $/ \mathrm{kg}$ dry matter in the open sun. The final moisture contents represent moisture equilibrium between the sample and drying air conditions, beyond which any changes in the mass of the sample could not occur.

Drying times were respectively about 73 hours ( 3 days) in the dryer, 79 hours in the greenhouse and 118 hours (5 days) in open sun (Fig. 7). The pepper dries faster in the dryer. It takes 50 hours (2 days) to dry pepper following marketing standards having water content of $17.2 \%$ wet basis, corresponding in dry basis to $\mathrm{X}=0.2 \mathrm{~kg}$ water/kg dry matter. However, the two other methods take much more time, and cannot reach the marketing standards.

The examination of fig.7 shows that the drying kinetics of the red pepper are characterized by a significant acceleration during day time. The solar radiation intensity acts directly on the product temperature through the heat flux carried by radiation, which consequently favors the internal mass transfers. The increase in product temperature does not only change the water activity but also influences the moisture diffusion coefficient and, with a lesser extent, the enthalpy of vaporization. This result is consistent with the observations of Passamia and Saravia [11, 12], Kaymak-Ertekin [19], TundeAkintunde et al. [5], Akpinar and Bicer [4].

The curves in Fig.7 are characterized by stops of drying at night. During these periods, the internal temperature gradient and the moisture content in the product relieve as was the case in works presented by Toĝrul and Pehlivan [18] and Dissa et al. [29]. The temperatures and the moisture contents in the product tend to be uniform. Hence, the surface water tends to increase because the water surges from the center towards the periphery of the product. Consequently at the product surface, the water activity increase and the temperature decrease. With sunrise in the morning, the internal temperature gradient and the moisture content go crescendo.

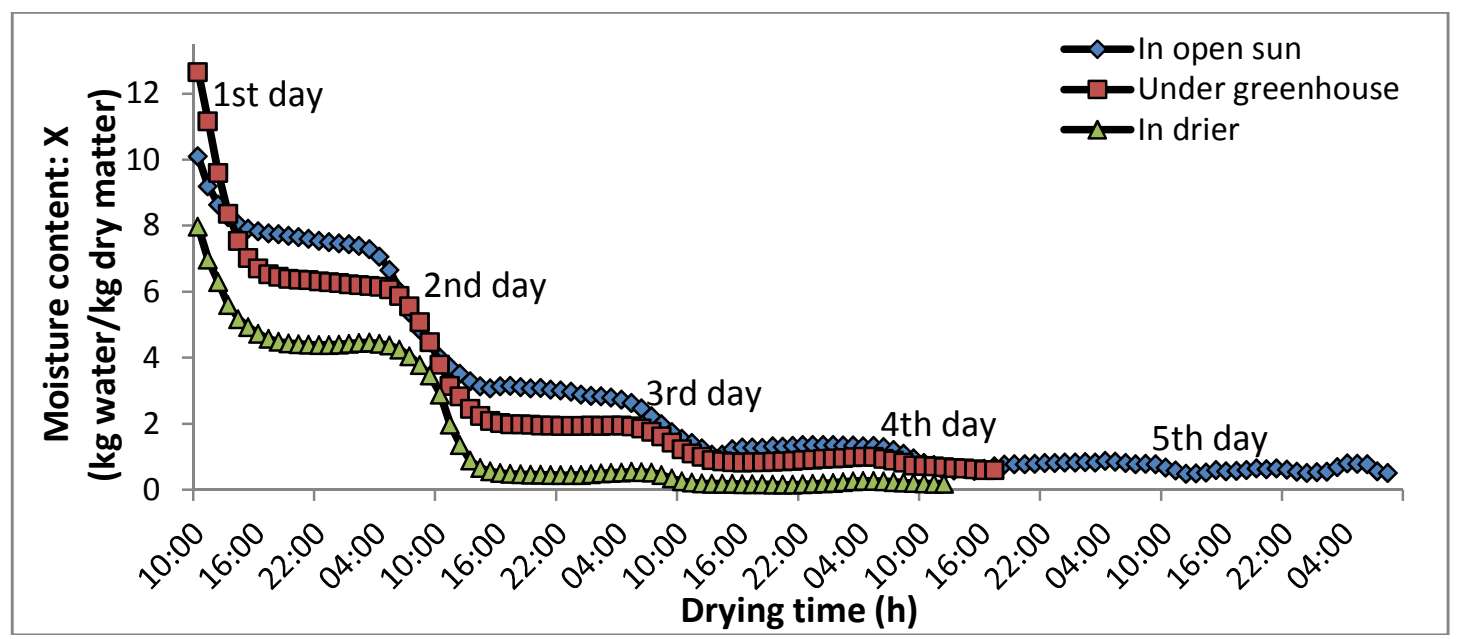

Fig.7. Variation of Moisture Content versus Drying Time

The drying rates versus drying time are shown in Fig. 8. The drying rate was at maximum in midday and at minimum (about zero) in the early morning (before $05 \mathrm{~h}$ local time) and late afternoon (after $16 \mathrm{~h}$ local time). These maximums drying rate decrease with time. During the day, there is not any constant-rate drying period in these curves and all the drying operations are seen to occur in the falling rate period (period 2). During the falling drying rate period, the surface water on the product will decrease. There is no free water on the product surface. Capillary 
forces impede the migration of water toward the surface. The moisture diffusion is controlled by internal liquid movement while surface becomes continuously depleted in water. This result is in agreement with observations of Dissa et al. [29], Akpinar [20] and Toĝrul and Pehlivan [18].

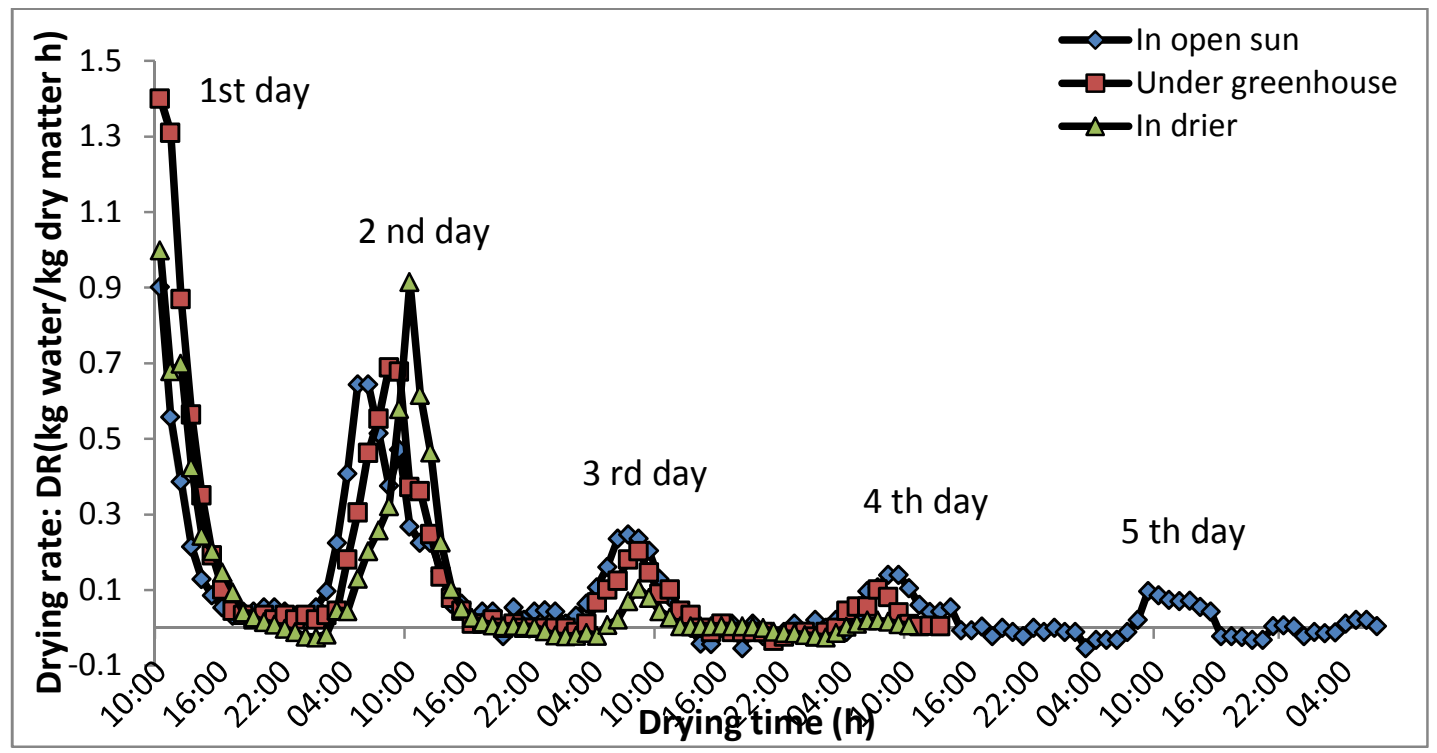

Fig. 8. Variation of Drying Rate versus Drying Time

The drying rates versus moisture content are shown in Figs. 9a, 9b and 9c. The drying rate was fluctuating very much with moisture content especially in open sun. The drying in open sun takes more time because of the lesser rate of water evaporated during the day. At night, the decrease in the temperature of the product compared to that of the air and the increases in the relative humidity of the air around the product have the effect to reverse the difference in water vapor partial pressure. This involves a light increase in moisture content of the product during night and more fluctuation in the drying rates.

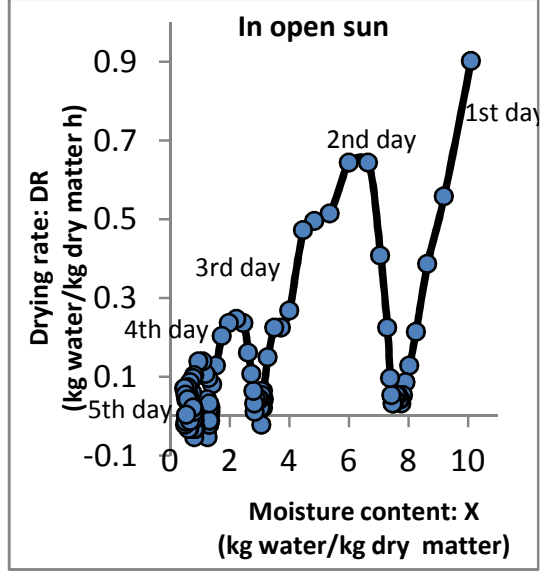

Fig. 9a. Variation of Drying Rate as a Function of Moisture Content for Pepper in Open Sun

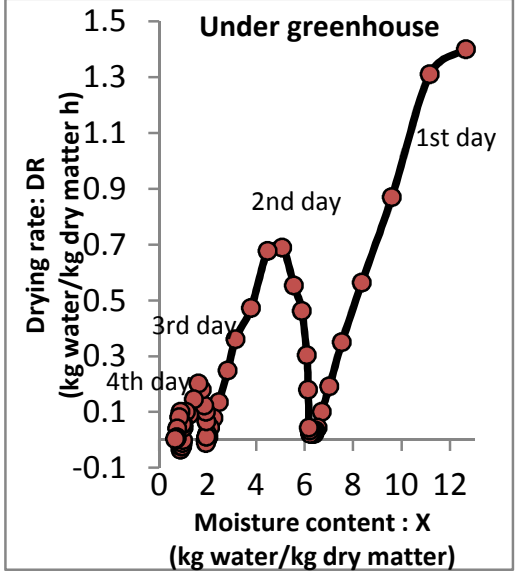

Fig. 9b. Variation of Drying Rate as a Function of Moisture Content for Pepper under Greenhouse

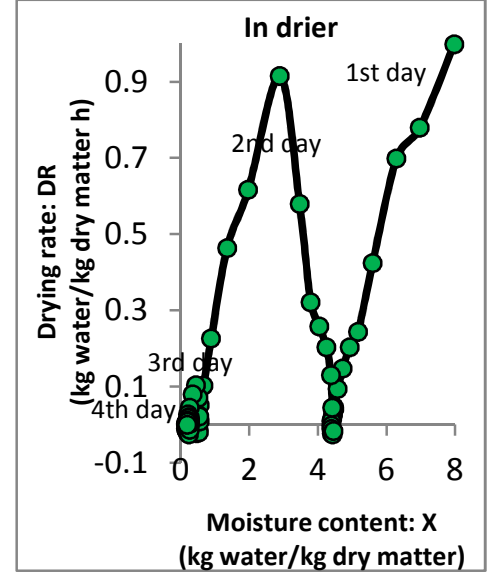

Fig. 9c. Variation of Drying Rate as a Function of Moisture Content for Pepper in Solar Drier 
In order to normalize the drying curves, the data involving the dry basis moisture content versus drying time were transformed to a dimensionless parameter called the moisture ratio versus time (Fig. 10). The drying data as the moisture ratio (XR) versus drying time were fitted to the six drying models presented by previous workers (Table1). The results of the statistical analysis undertaken on these models for solar drying in the drier, in open sun and under greenhouse are given in Tables 3, 4 and 5, respectively. The models were evaluated based on $\mathrm{R}^{2}, \chi^{2}$ and RMSE. The model that best predicts the drying process will have higher value of $\mathrm{R}^{2}$ and lower values of $\chi^{2}$ and RMSE. The logarithmic model was found to be the most suitable model for describing the drying curve of the thin layer of red pepper by the three drying processes, as shown in Tables 3, 4 and 5. For the solar drying of peppers in the drier, the logarithmic model gave $\mathrm{R}^{2}=0.90552, \chi^{2}=0.00733$ and RMSE $=0.08559$. For the solar drying of peppers in open sun the logarithmic model gave $\mathrm{R}^{2}=$ $0.9658, \chi^{2}=0.00259$ and RMSE $=0.05085$. For the solar drying of peppers under greenhouse the logarithmic model gave $\mathrm{R}^{2}$ $=0.94392, \chi^{2}=0.00316$ and $\mathrm{RMSE}=0.05621$.

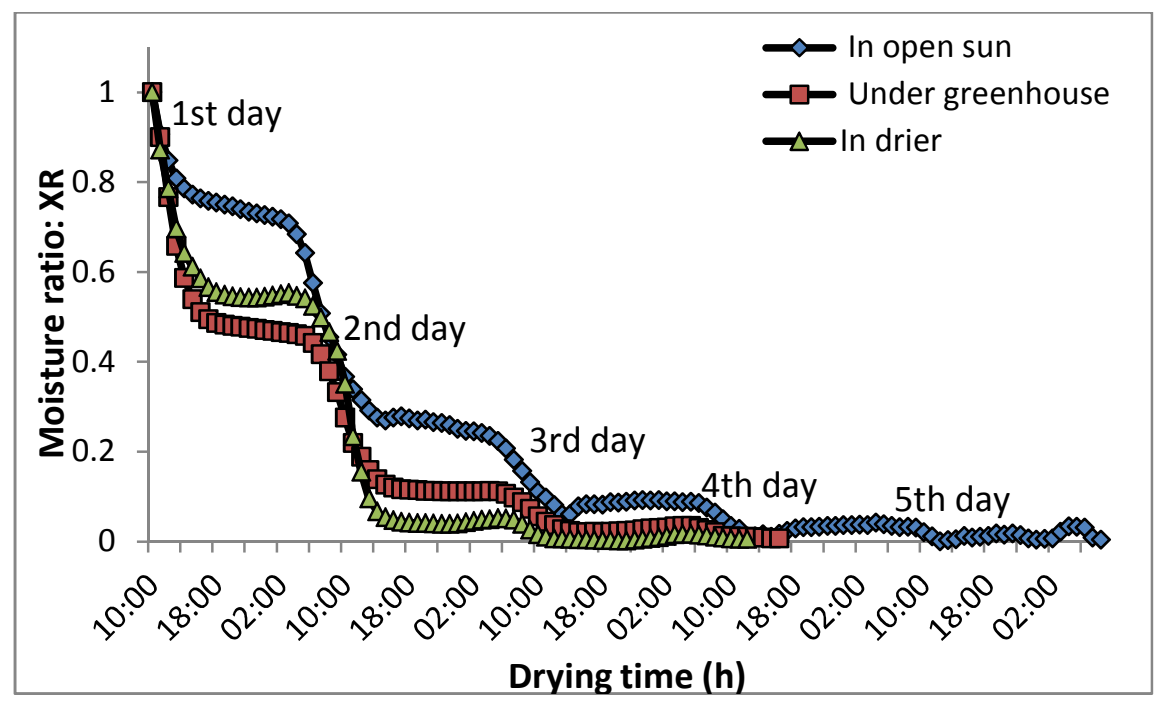

Fig. 10. Variation of Moisture Ratio versus Drying Time

Table 3. Modelling of Moisture Ratio according to Drying Time for Thin Layer Convective Solar Drying of Red Peppers

\begin{tabular}{|c|c|c|c|c|}
\hline Model no. & Model constants & $\mathbf{R}^{2}$ & $\chi^{2}$ & RMSE \\
\hline 1 & $\mathrm{k}=0.05837$ & 0.88904 & 0.00837 & 0.09149 \\
\hline 2 & $\mathrm{a}=0.94208 ; \mathrm{k}=0.05531$ & 0.89229 & 0.00824 & 0.09076 \\
\hline 3 & $a=0.98796 ; k=0.04359 ; c=-0.08125$ & 0.90552 & 0.00733 & 0.08559 \\
\hline 4 & $\begin{array}{lll}\mathrm{a}=0.47104 ; & \mathrm{k}_{0}=0.0552972 ; & \mathrm{b}=0.47104 ; \\
\mathrm{k}_{1}=0.0553017 & & \end{array}$ & 0.89229 & 0.00847 & 0.09203 \\
\hline 5 & $a=-0.03826 ; b=3.522910^{-4}$ & 0,89323 & 0,00817 & 0.09036 \\
\hline 6 & $\begin{array}{lcl}a=0.31403 ; & k=0.0552982 ; & b=0.31403 ; \\
g=0.0552982 ; c=0.31403 ; & h=0.0553021\end{array}$ & 0.89229 & 0.00871 & 0.09335 \\
\hline
\end{tabular}


Table 4. Modelling of Moisture Ratio according to Drying Time for Thin Layer Open Sun Drying of Red Peppers

\begin{tabular}{|c|c|c|c|c|}
\hline Model no. & Model constants & $\mathbf{R}^{2}$ & $\chi^{2}$ & RMSE \\
\hline 1 & $\mathrm{k}=0.03734$ & 0.96331 & 0.00273 & 0.05222 \\
\hline 2 & $\mathrm{a}=1.02624 ; \mathrm{k}=0.03826$ & 0.96391 & 0.00271 & 0.05202 \\
\hline 3 & $\mathrm{a}=1.03621 ; \mathrm{k}=0.03534 ; \mathrm{c}=-0.02547$ & 0.96582 & 0.00259 & 0.05085 \\
\hline 4 & $\begin{array}{l}\mathrm{a}=0.51312 ; \quad \mathrm{k}_{0}=0.03826187 ; \mathrm{b}=0.51312 ; \\
\mathrm{k}_{1}=0.038261407\end{array}$ & 0.96391 & 0.00275 & 0.05247 \\
\hline 5 & $a=-0.02433 ; b=1.4345410^{-4}$ & 0.94184 & 0,00436 & 0.06602 \\
\hline 6 & $\begin{array}{l}a=0.34208 ; \quad k=0.038263861 ; \quad b=0.34208 ; \\
g=0.038263861 ; c=0.34208 ; h=0.038257171\end{array}$ & 0.96391 & 0.00282 & 0.05293 \\
\hline
\end{tabular}

Table 5. Modelling of Moisture Ratio according to Drying Time for Thin Layer Greenhouse Drying of Red Peppers

\begin{tabular}{|c|c|c|c|c|}
\hline Model no. & Model constants & $\mathbf{R}^{2}$ & $\chi^{2}$ & RMSE \\
\hline 1 & $\mathrm{k}=0.06014$ & 0.91572 & 0.00463 & 0.06802 \\
\hline 2 & $\mathrm{a}=0.85197 ; \mathrm{k}=0.0511$ & 0.94201 & 0.00323 & 0.05679 \\
\hline 3 & $\mathrm{a}=0.86575 ; \mathrm{k}=0.046309052 ; \mathrm{c}=-0.02658$ & 0.94392 & 0.00316 & 0.05621 \\
\hline 4 & $\begin{array}{l}\mathrm{a}=0.42599 ; \quad \mathrm{k}_{0}=0.051098124 ; \quad \mathrm{b}=0.42599 ; \\
\mathrm{k}_{1}=0.051097158\end{array}$ & 0.94201 & 0.00331 & 0.05754 \\
\hline 5 & $a=-0.03687 ; b=3.3045310^{-4}$ & 0.89717 & 0,01031 & 0.10152 \\
\hline 6 & $\begin{array}{l}a=0.28399 ; \quad k=0.051097628 ; \quad b=0.28399 ; \\
g=0.051097628 ; c=0.28399 ; h=0.051097654\end{array}$ & 0.94201 & 0.00341 & 0.05833 \\
\hline
\end{tabular}

\section{Conclusion}

This study led us to draw some conclusions on experiments in open sun, under greenhouse and in a drier where drying conditions are variable and uncontrolled. Red pepper dried faster in the dryer than in open sun and under greenhouse. It takes 50 hours to dry pepper following the marketing standards. However, the drying in open sun and under greenhouse takes much more time, about 79 hours in the greenhouse and 118 hours in open sun, and cannot reach the marketing standards. During the day, the air temperatures around the product in the drier and in the greenhouse are close and higher than the ambient air temperature. In open air and in the greenhouse, the product temperatures are higher than the drying air temperatures. However, in the drier, the drying air temperature is higher than the product temperature. The relative humidity of the air inside the drier is lower than that inside the greenhouse and in open sun. Low relative humidity is more favourable for drying due to the increase of the evaporating capacity of the air. During the night, relative humidity of the air inside the drier and relative humidity inside the greenhouse were higher than that of air in open sun. The excessive increase in the relative humidity of the air, during the night in the drier and inside the greenhouse can increase the moisture content of the product. During the day, there is not any constant-rate drying period in these curves and all the drying operations are seen to occur in the falling rate period. The logarithmic model was found to be the most suitable model for describing the drying curve of the thin layer of red pepper by the three drying processes.

The solar tunnel greenhouse dryer can be improved to become more competitive to the solar air dryer, by increasing inside air temperature and then reducing the inside air humidity through the using of solar air heater. Further studies are ongoing. 


\section{Acknowledgements}

This research was supported by the Ministry of Higher Education, Scientific Research and Technology, Republic of Tunisia.

\section{References}

[1] Kaensup, W., Wongwises, S. \& Chutima, S. (1998). "Drying of Pepper Seeds Using a Combined Microwave/Fluidized Bed Dryer," Drying Technology: An International Journal 16, 853-862.

[2] Vega-Galvez, A., Lemus-Mondacs, R., Bilbao-Sailnz, C., Fito, P. \& Andres, A. (2008). "Effect of Air Drying Temperature on the Quality of Rehydrated Dried red Bell Pepper (var. Lumuyo)," Journal of Food Engineering 85, 42-50.

[3] A. S. A. (2010). 'Annulaire des Statiques Agricoles. République Tunisienne Ministère de l'Agriculture, de l'Environnement et des Ressources Hydrauliques, 'Tunisie, Novembre 2010.

[4] Kavak Akpinar, E. \& Bicer, Y. (2008). "Mathematical Modelling of Thin Layer Drying Process of Long Green Pepper in Solar Dryer and under Open Sun," Energy Conversion and Management 49 ; 13671375.

[5] Tunde-Akintunde, T. Y., Afolabi, T. J. \& Akintunde, B. O. (2005). "Influence of Drying Methods on Drying of Bell-Pepper (Capsicum Annuum)," Journal of Food Engineering 68; 439-442.

[6] Doymaz, I. \& Pala, M. (2002). "Hot-air Drying Characteristics of Red Pepper," Journal of Food Engineering 55, 331-335.

[7] Ergüneş, G. \& Tarhan, S. (2006). “Color Retention of Red Peppers by Chemical Pretreatments during Greenhouse and Open Sun Drying," Journal of Food Engineering 76, 446-452.

[8] Tunde-Akintunde, T. Y. (2011). "Mathematical Modeling of Sun and Solar Drying of Chilli Pepper," Renewable Energy 36, 2139-2145.
[9] Arslan, D. \& Özcan, M. M. (2011). "Dehydration of Red Bell-Pepper (Capsicum Annuum L.): Change in Drying Behavior, Colour and Antioxidant Content," Food and Bioproducts Processing 89, 504513.

[10] Belessiotis, V. \& Delyannis, E. (2011). “Solar Drying," Solar Energy 85, 1665-1691.

[11] Farhat, A., Kooli, S., Kerkeni , C., Maalej, M., Fadhel, A. \& Belghith, A. (2004). "Validation of a Pepper Drying Model in a Polyethylene Tunnel Greenhouse," International Journal of Thermal Sciences 43, 53-58.

[12] Passamia, V. \& Saravia, L. (1997a). "Relationship between a Solar Drying Model of Red Pepper and the Kinetics of Pure Water Evaporation (I)," Drying Technology: An International Journal 15, 1419-1432.

[13] Passamia, V. \& Saravia, L. (1997b). "Relationship between a Solar Drying Model of Red Pepper and the Kinetics of Pure Water Evaporation (II)," Drying Technology: An International Journal 15, 1433-1445.

[14] Sacilik, K., Keskin, R. \& Elicin, A. K. (2006). "Mathematical Modeling of Solar Tunnel Drying of Thin Layer Organic Tomato," Journal of Food Engineering 73, 231-238.

[15] Rathore, N. S. \& Panwar, N. L. (2010). "Experimental Studies on Hemi Cylindrical Walk-In Type Solar Tunnel Dryer for Grape Drying," Applied Energy 87, 2764-2767.

[16] Kooli, S., Fadhel, A., Farhat, A. \& Belghith, A. (2007). "Drying of Red Pepper in Open Sun and Greenhouse Conditions: Mathematical Modelling and Experimental Validation," Journal of Food Engineering 55, 1094-1103.

[17] Kaewkiew, J., Nabnean, S. \& Janjai, S. (2012). "Investigation of the Performance of a Large-Scale Greenhouse Type Solar Dryer for Drying Chilli in Thailand," Procedia Engineering 32, 433-439. 
[18] Toĝrul, ĺ. T. \& Pehlivan, D. (2004). "Modelling of Thin Layer Drying Kinetics of Some Fruits under Open-Air Sun Drying Process," Journal of Food Engineering 65, 413-425.

[19] Kaymak-Ertekin, F. (2002). "Drying and Rehydrating Kinetics of Green and Red Peppers," Journal of Food Science 67, 168175.

[20] Akpinar, E. K. (2010). “Drying of Mint Leaves in a Solar Dryer and under Open Sun: Modelling, Performance Analyses," Energy Conversion and Management 51, 2407-2418.

[21] Günhan, T., Demir, V., Hancioglu, E. \& Hepbasli, A. (2005). "Mathematical Modelling of Drying of Bay Leaves," Energy Conversion and Management 46, 16671679.

[22] Menges, H. O. \& Ertekin, C. (2006). "Thin Layer Drying Model for Treated and Untreated Stanley Plums," Energy Conversion and Management 47, 23372348.

[23] Mujumdar, A. S. (1987). Handbook of Industrial Drying, New York: Marcel Dekker.

[24] Henderson, S. M. \& Pabis, S. (1961). 'Grain Drying Theory. II. Temperature Effects on Drying Coefficients,' Journal of Agricultural Engineering Research 6, 169174.

[25] Singh, S., Sharma, R., Bawa, A. S. \& Saxena, D. C. (2008). "Drying and Rehydration Characteristics of Water Chestnut (Trapanatans) as a Function of Drying Air Temperature," Journal of Food Engineering 87, 213-221.

[26] Henderson, S. M. (1974). "Progress in Developing the Thin Layer Drying Equation," Transactions of the America Society Agricultural Engineering 17, 11671172.

[27] Wang, C. \& Singh, R. A. (1978). 'A Single Layer Drying Equation for Rough Rice,' ASAE Paper 78-3001. St. Joseph (MI): America Society Agricultural Engineering.
[28] Karathanos, V. T. (1999). "Determination of Water Content of Dried Fruits by Drying Kinetics," Journal of Food Engineering 39, 337-344.

[29] Dissa, A. O., Bathiebo, D. J., Desmorieux, H., Coulibaly, O. \& Koulidiati, J. (2011). "Experimental Characterisation and Modelling of Thin Layer Direct Solar Drying of Amelie and Brooks Mangoes," Energy 36, 2517-2527. 